\title{
ANALISA RISIKO K3 PADA OPERATOR ROLLING MILL DENGAN PENDEKATAN HAZARD AND OPERABILITY STUDY (HAZOP) (study kasus di PT. XYZ)
}

\author{
Sarifudin Mochamad \\ e-mail : mosyamosya22@gmail.com \\ Teknik Industri, Fakultas Teknik \\ Universitas Maarif Hasyim Latif
}

\begin{abstract}
ABSTRAK
Penerapan standarisasi serta prosedur keselamatan dan kesehatan kerja (K3) telah dilakukan oleh PT. XYZ, namun dalam pelaksanaannya masih terdapat beberapa potensi bahaya khususnya pada departemen Rolling Mill. Putaran mesin dengan kecepatan tinggi serta banyaknya material panas menjadi salah satu penyebab terjadinya kecelakaan kerja. Apabila kecelakaan kerja terjadi maka risiko yang ditimbulkan bervariasi dari risiko cedera ringan hingga risiko cedera yang serius, sehingga perlu diidentifikasi serta pengendalian potensi bahaya tersebut. Dengan menggunakan pendekatan metode Hazard And Operability Study (HAZOP), penelitian ini bertujuan untuk menganalisa dan mengidentifikasi sumber - sumber Hazard yang ada pada PT. XYZ khusunya depertemen Rolling Mill. Metode HAZOP terdapat beberapa parameter diantaranya likelihood, consequences, dan risk matrix yang menjadi standar dalam menentukan nilai dan tingkatan bahaya pada setiap komponen. Pada Departemen Rolling Mill ditemukan 42 potensi bahaya (hazard) kemudian digolongkan menjadi 16 sumber hazard. Dari masing-masing sumber potensi bahaya tersebut dilakukan kombinasi parameter yaitu dengan mengalikan nilai Likelihood dan nilai Consequence sehingga diperoleh tingkat bahaya (risk level) diantaranya terdapat 3 sumber hazard yang memiliki nilai ekstrim, 7 sumber hazard yang memiliki nilai risiko tinggi, 6 sumber hazard yang memiliki nilai risiko sedang, dan 3 sumber hazard yang memiliki nilai risiko rendah. Untuk mengurangi jumlah kecelakaan kerja karyawan serta meningkatkan nilai Safety pada lantai produksi Rolling Mill, maka sumber Hazard yang memiliki risiko ekstrim yaitu Sikap pekerja, Mesin Roll dan Handling Bed diprioritaskan untuk mendapatkan rekomendasi atau usulan perbaikan terlebih dahulu.
\end{abstract}

Kata kunci: HAZOP, K3, Risk Matriks, Risko, Rolling Mill

\section{PENDAHULUAN}

Suatu perusahaan berkewajiban mengusahakan agar karyawan memiliki kesadaran tentang pentingnya keselamatan dan kesehatan dalam bekerja. Demi kelancaran dan kemajuan perusahaan, maka Perusahaan yang baik adalah perusahaan yang benarbenar menjaga keselamatan dan kesehatan kerja karyawannya (Wartono et al., 2017). Disamping itu untuk meminimalisir kecelakaan kerja karyawan bagi perusahaan merupakan hal yang wajib dilakukan guna menjaga standardisasi perusahaan di bidang keselamatan dan kesahatan kerja.

PT. XYZ adalah suatu perusahaan yang bergerak di bidang peleburan dan pengerolan logam yang bertempat di Sidoarjo dan menghasilkan produk berupa besi beton. Dalam pelaksanaan produksinya pada Departemen Rolling Mil karyawan dihadapkan langsung dengan material panas dan pijar pada saat proses peleburan dan pengerolan logam. Sifat panas dan pijar bahan baku logam serta mesin-mesin dengan putaran tinggi memiliki potensi bahaya serta risiko besar bagi karyawan sehingga proses ini bersifat hazardous dan perlu dilakukan identifikasi bahaya yang berguna untuk mencegah terjadinya kecelakaan dalam bekerja.

Untuk mengidentifikasi tingkat hazard, penelitian ini menggunakan metode Hazard And Operability Study (HAZOP) yaitu suatu metode yang berfungsi menganalisa dan mengidentifikasi risiko - risiko yang ada dalam proses produksi. Sehingga diharapkan dapat dilakukan upaya pencegahan serta mengurangi terjadinya kecelakaan kerja (accident) karyawan yang terjadi di perusahaan serta menanggulangi risiko tersebut dengan cara yang tepat.

\section{METODE PENELITIAN}

Penelitian ini menggunakan jenis penelitian diskriptif yang mana dilakukan untuk mendiskripsikan atau menggambarkan suatu fenomena yang ada dimasyarakat. Tahap pendahuluan digunakan untuk mengetahui kondisisuatu tempat yang akan diteliti serta dapat mengetahui karakteristik permasalahannya, selain itu pengumpulan data juga diperlukan untuk memperoleh informasi - informasi yang dibutuhkan dalam penelitian. Observasi ini diawali dengan mengidentifikasi risiko kecelakaan kerja pada proses produksi pengerollan, yaitu dari awal proses bahan 
baku dimasukkan ke furnace hingga pengepakkan produk jadi besi beton, selain itu observasi ini juga mengidentifikasi kegiatan karyawan produksi dalam pengoprasian alat - alat bantu produksi seperti mesin bubut, mesin gerinda, mesin las, dan Brander Oxi Acetyline (BOA).

Pada obsevasi ini berfokus pada perbaikan penerapan prosedur Keselamatan dan Kesehatan Kerja pada PT. XYZ dengan menggunakan pendekatan metode HAZOP.menurut Prakoso (2018) dengan menggunakan metode HAZOP dapat memberikan parameter parameter tentang tingkatan sumber bahaya yang bisa dijadikan prioritas serta usulan perbaikan pada item atau bagian dari suatu proses yang mengalami penyimpangan dari desain yang telah ditentukan. Metode HAZOP merupakan metode kualitatif yang mudah dipelajari, sistematis dan memperoleh hasil yang teliti (Retnowati, 2017).

Dalam menganalisa dan mengidentifikasi sumber Hazard dengan menggunakan HAZOP worksheet dan Risk Assessment adalah sebagai berikut :

1. Memahami urutan - urutan proses pada area yang akan diteliti.

2. Mengidentifikasi sumber Hazard yang telah ditemukan pada area penelitian.

3. Melengkapi kriteria - kriteria yang terdapat pada worksheet yaitu mengklasifikasikan sumber Hazard yang telah ditemukan.

4. Mendeskripsikan penyimpangan yang terjadi selama proses produksi.

5. Menilai risiko yang timbul dengan parameter yang menjadi standar dalam menentukan tingkatan bahaya pada setiap item atau komponen

6. Melakukan perangkingan dari sumber Hazard yang telah didefinisikan dengan memperhitungkan likelihood dan consequences dengan menggunakan risk matriks untuk mengetahui sumber Hazard yang sebaiknya diprioritaskan terlebih dahulu (seperti pada Gambar 1).

7. Memberikan usulan perbaikan untuk risiko yang memiliki nilai "Ekstrim"

Parameter yang menjadi standar metode HAZOP diantaranya :

\section{Likelihood}

merupakan peluang risiko terjadinya bahaya atau konsekuensi pada item atau komponen dengan sistem pengaman yang ada. (seperti pada Tabel 1).

\section{Consequences}

Merupakan tingkat yang menunjukkan keparahan cedera yang dialami oleh pekerja yang didefinisikan secara kualitatif serta hari kerja yang hilang akibat cedera tersebut. (seperti pada Tabel 2)

3. Risk Level

Risk Level atau risiko merupakan nilai risiko yang didapatkan dari hasil pengalian nilai likelihood dengan nilai Consequences yang nantinya akan dijadikan sebagai rekomendasi perbaikan yang sesuai dengan permasalahan yang ada. Nilai risiko itu sendiri dapat dilakukan dengan menggunakan risk matriks.

Tabel 1. Kriteria likelihood

\begin{tabular}{|c|c|c|c|}
\hline \multicolumn{2}{|c|}{ Level } & \multirow{2}{*}{ Criteria } & \multicolumn{2}{c|}{ likelihood } \\
\cline { 3 - 4 } & Jescription \\
\hline 1 & Jarang terjadi & $\begin{array}{c}\text { Dapat dipikirkan tetapi } \\
\text { tidak hanya saat keadaan }\end{array}$ & $\begin{array}{c}\text { Kurang dari } 1 \text { kali } \\
\text { per } 10 \text { tahun }\end{array}$ \\
\hline 2 & Kemungkinan terjadi & $\begin{array}{c}\text { Belum terjadi tetapi bisa } \\
\text { muncul/terjadi pada suatu } \\
\text { waktu }\end{array}$ & $\begin{array}{c}\text { Terjadi } 1 \text { kali per } \\
10 \text { tahun }\end{array}$ \\
\hline 3 & Mungkin & $\begin{array}{c}\text { Seharusnya terjadi dan } \\
\text { mungkin telah } \\
\text { terjadi/muncul disini atau } \\
\text { ditempat lain }\end{array}$ & $\begin{array}{c}1 \text { kali per } 5 \text { tahun } \\
\text { sampai } 1 \text { kali per } \\
\text { tahun }\end{array}$ \\
\hline 4 & Kemugkinan besar & $\begin{array}{c}\text { Dapat terjadi dengan } \\
\text { mudah, mungkin muncul } \\
\text { dalam keadaan yang paling } \\
\text { hanvakteriadi }\end{array}$ & $\begin{array}{c}\text { Lebih dari } 1 \text { kali } \\
\text { per tahun hingga } \\
1 \text { kali per bulan }\end{array}$ \\
\hline 5 & Hampir pasti & $\begin{array}{c}\text { Sering terjadi, diharapkan } \\
\text { munculdalam keadaan } \\
\text { yang paling sering terjadi }\end{array}$ & $\begin{array}{c}\text { Lebih dari } 1 \text { kali } \\
\text { per bulan }\end{array}$ \\
\hline
\end{tabular}

Sumber : UNSW Health and Safety (2008)

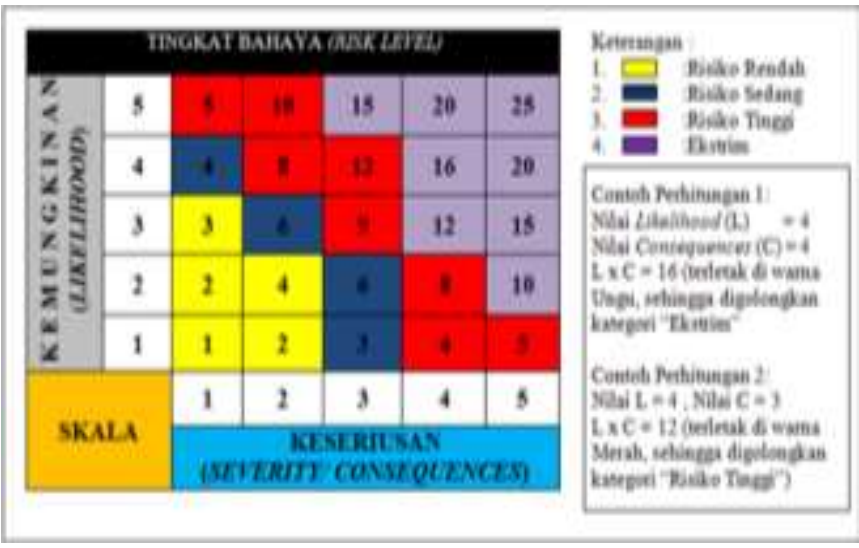

Gambar 1. Risk Matrix

Sumber : UNSW Health and Safety (2008) 
Tabel 2. Kriteria Consequences

\begin{tabular}{|c|c|c|c|}
\hline \multirow{2}{*}{ Level } & \multirow{2}{*}{ Uraian } & \multicolumn{2}{|c|}{ Consequences } \\
\cline { 3 - 4 } & Tidak signifikan & $\begin{array}{c}\text { Kejadian tidak } \\
\text { menimbulkan } \\
\text { kerugian atau cedera } \\
\text { pada manusia }\end{array}$ & $\begin{array}{c}\text { Tidak } \\
\text { menyebabkan } \\
\text { kehilangan hari } \\
\text { kerja }\end{array}$ \\
\hline 2 & Kecil & $\begin{array}{c}\text { Menimbulkan cedera } \\
\text { ringan, kerugian kecil } \\
\text { dan tidak } \\
\text { menimbulkan dampak } \\
\text { serius terhadap } \\
\text { kelangsungan bisnis }\end{array}$ & Masih dapat \\
berja pada hari / \\
shift yang sama
\end{tabular}

Sumber : UNSW Health and Safety (2008)

\section{HASIL DAN PEMBAHASAN}

Obyek pengamatan dalam penelitian ini adalah lantai produksi di PT. XYZ, yang difokuskan pada Departemen Rolling Mill. Jenis kegiatan produksi yang berlangsung di PT. XYZ yakni make to stock (MTS), yaitu operasi yang difokuskan pada kebutuhan pemenuhan stok pada gudang penyimpanan dengan memperhatikan tingkat persediaan dan juga permintaan diwaktu yang akan dating.

Sesuai dengan pokok bahasan pada tugas akhir ini yaitu analisis risiko K3 pada operator Rolling Mill 3 maka dilakukan pengumpulan data yang diperoleh dengan mencari sumber data primer dan sekunder. Data primer didapatkan dengan cara observasi langsung di area produksi Rolling Mill PT. XYZ mulai dari proses pemanasan baham baku billet hingga proses packaging serta mengamati atau mendokumentasikan hazard yang ditemukan di lapangan. Data skunder diperoleh dari database Health Safety Environment (HSE) mengenai kecelakaan kerja yang terjadi selama 4 tahun terakhir di area produksi Rolling Mill 3 seperti yang terlihat pada Gambar 2 dibawah ini

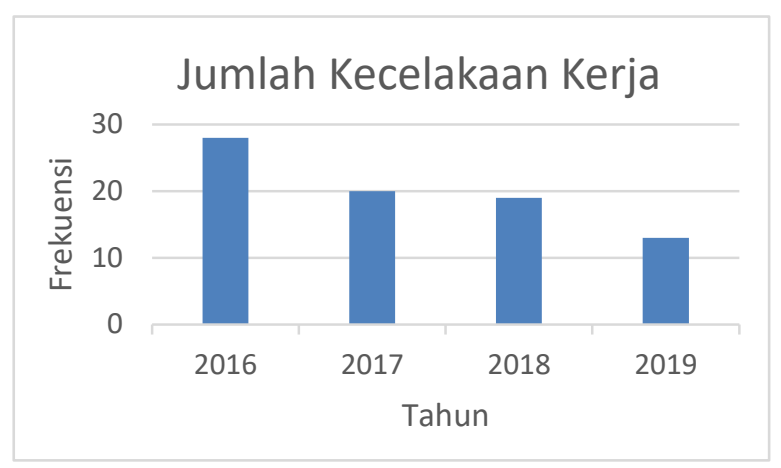

Gambar 2. Jumlah kecelakaan kerja pada tahun 2016-2019

Sumber PT. XYZ

Menurut data kecelakaan kerja perusahaan, mulai tahun 2016 sampai 2019 (seperti pada Gambar 2) terdapat 77 kasus kecelakaan kerja sedang dan 3 kasus kecelakaan kerja berat. Kecelakaan tersebut dipengaruhi beberapa faktor seperti keadaan lingkungan kerja, tindakan pekerja, maupun kondisi fisik pekerja.

Hasil observasi lapangan menemukan sebanyak 42 temuan potensi bahaya yang terdiri 29 temuan potensi bahaya yang disebabkan oleh unsafe act atau perilaku manusia tidak aman saat sedang melakukan pekerjaan diantaranya sebagai berikut :

1. Tidak memakai helm saat bekerja

2. Mengantuk saat bekerja

3. Kondisi badan kurang sehat saat bekerja

4. Bekerja dengan tergesa - gesa

5. Memakai headset saat bekerja

6. Menggunakan hp saat bekerja

7. Bercanda saat bekerja

8. Tidak memakai masker saat menggerinda

9. Tidak memakai masker saat mengelas

10. Tidak memakai masker saat menggunakan BOA

11. Kurang konsentrasi saat menggunakan crane

12. Memakai sepatu karet pada area kerja Handling Bed

13. Memakai sandal di area Handling Bed

14. Memakai sandal di area Conveyor

15. Berlalu lalang di area shear

16. Berlalu lalang di area Mesin Roll

17. Memakai kaos oblong pada area Handling Bed

18. Tidak memakai sarung tangan kulit saat menggunakan BOA

19. Tidak memakai kacamata saat menggunakan BOA

20. Memakai kaos oblong saat mengelas

21. Tidak memakai sarung tangan kulit saat mengelas 
22. Tidak memakai pelindung kepala /teropong saat mengelas

23. Kondisi tangan basah saat mengelas

24. Tidak memakai cover sepatu pada area handling Bed

25. Tidak memakai sarung tangan saat menggunakan mesin bor

26. Tidak memakai kacamata saat menggerinda

27. Tidak menggunakan kacamata saat menggunakan mesin bubut

28. Memakai sepatu karet pada area stapel

29. Acuh pada teman kerja

Kemudian 13 temuan potensi bahaya yang disebabkan oleh unsafe condition atau kondisi lingkungan kerja yang tidak aman antara lain :

1. Holder las rusak

2. Teropong las kondisi rusak

3. Selang BOA bocor

4. Regulator BOA bocor

5. Posisi tabung oksigen / LPG tidak berdiri

6. Area las basah

7. Penggunaan batu gerinda yang tidak sesuai

8. Terjadi missroll pada mesin roll

9. Roll pada Handling Bed abnormal

10. Lantai plat pada area Handling Bed keropos

11. Roll pada area Coolling Bed keropos

12. Kondisi besibeton yang masih panas (pada area stapel)

13. Rantai Conveyor abnormal

Kemudian untuk mempermudah dalam pengolahan data selanjutnya 42 temuan potensi bahaya yang terdiri 29 temuan potensi bahaya yang disebabkan oleh unsafe act dan 13 temuan potensi bahaya yang disebabkan oleh unsafe condition digolongkan berdasarkan jenis sumbernya menjadi 16 sumber bahaya yang dapat dilihat pada Tabel 3

Tabel 3. Hazard berdasarkan sumbernya

\begin{tabular}{|c|c|c|}
\hline no & Sumber Hazard & Jumlah Temuan \\
\hline 1 & Sikap pekerja & 8 \\
\hline 2 & Kondisi Lantai & 4 \\
\hline 3 & Pengelasan & 3 \\
\hline 4 & Brander Oxi Acetylene & 2 \\
\hline 5 & Mesin Bubut & 1 \\
\hline 6 & Gerinda (hand Grinding) & 2 \\
\hline 7 & Mesin Gerinda & 1 \\
\hline 8 & Shear & 1 \\
\hline 9 & Hoistcrane & 1 \\
\hline 10 & Mesin Bor & 3 \\
\hline 11 & Panel & 4 \\
\hline 12 & Mesin Roll & 3 \\
\hline 13 & Handling Bed & 2 \\
\hline 14 & Coolling Bed & 3 \\
\hline 15 & Conveyor & 42 \\
\hline 16 & Stapel & \\
\hline & Jumlah & 3 \\
\hline
\end{tabular}

Dari tabel 3 menjelaskan bahwa terdapat 42 temuan potensi di area Rolling Mill yang kemudian digolongkan menjadi 16 jenis sumber bahaya meliputi Sikap pekerja, Kondisi lantai, Pengelasan, Brander oxi acetylene, Mesin bubut, Gerinda (hand grinding), Mesin gerinda, Shear, Hoistcrane, Bor, Panel listrik, Mesin roll, Handling Bed, Coolling Bed, Conveyor dan Stapel. Nilai temuan sumber bahaya tertinggi terjadi pada Sikap pekerja yang bekerja tidak sesuai dengan SOP sebanyak 8 temuan, Kondisi lantai rusak sebanyak 4 temuan, dan Handling Bed sebanyak 4 temuan. Sumber bahaya pada area Pengelasan, Brander Oxi Acetyline, Mesin roll, Cooling Bed, dan Stapel ditemukan sebanyak 3 temuan. Sumber bahaya pada area Mesin bubut, Mesin gerinda, dan Conveyor terdapat 2 temuan. Sedangkan Mesin gerinda (Hand Gerinda), Shear, Hoistcrane, Bor, dan Panel listrik masing- masing terdapat 1 temuan sumber bahaya.

Pada tahap berikutnya yaitu melakukan pengolahan dengan menggunakan metode Hazop dimana data temuan potensi bahaya yang telah terkumpul selanjutnya digolongkan berdasarkan jenis sumbernya untuk mendapatkan nilai Likelihood dan Consequence dari masing-masing sumber potensi bahaya. Tahap berikutnya adalah mengalikan nilai Likelihood dan nilai Consequence sehingga diperoleh tingkat bahaya (risk level) seperti yang terlihat pada tabel 4 dengan mempertimbangkan kreteria risiko sebagai berikut :

1. Likelihood (L) adalah probabilitas terjadinya kecelakaan ketika seseorang terpapar dengan bahaya

2. Severity atau Consequences adalah level/tingkat yang menunjukkan keparahan cidera seseorang dan kehilangan hari kerja

3. Risk Matrix adalah parameter perangkingan terhadap sumber hazard yang nantinya dapat digunakan untuk rekomendasi perbaikan.

\section{Hazop Analysis}

Setelah menentukan perangkingan risiko (Risk Level), langkah selanjutnya adalah menentukan Hazop Analysis dari Mesin roll dan Handling Bed yang bertujuan untuk mengidentifikasi atau menggambarkan proses operasi dari item- item Mesin roll dan Handling Bed sehingga dapat menentukan apakah proses operasi dari item tersebut terdapat penyimpangan sehingga mendorong ke arah kecelakaan kerja yang tidak diinginkan. Dengan menggunakan kombinasi antara Guideword (no, more, less, dll ) dan parameter proses operasi yang telah ditentukan, sehingga menghasilkan kemungkingan penyimpangan dari desain tersebut. 


\section{Hazop Analysis Mesin roll dan Handling Bed}

Hasil pengamatan dan wawancara terhadap operator Mesin roll, ditemukan part atau item ketika terjadi penyimpangan pada saat proses produksi akan menimbulkan kegagalan dalam proses pengerollan (missroll) sehingga bahan baku billet tidak sesuai pada lintasan roll. Hal ini menimbulkan sumber bahaya dikarenakan material dari billet missroll tersebut dalam keadaan panas. Disamping itu putaran mesin dengan kecepatan tinggi juga akan mendorong terjadinya kecelakaan kerja Pada item atau part yang terdapat pada mesin Handling Bed juga ditemukan sumber bahaya apabila terjadi penyimpangan dalam proses operasi mesin tersebut. Namun sumber bahaya yang berada pada area Handling Bed memiliki nilai risiko sedang.

Tabel 4. Perangkingan risiko

\begin{tabular}{|c|c|c|c|c|c|c|}
\hline \multirow{2}{*}{ No } & \multirow{2}{*}{ Sumber Hazard } & \multicolumn{3}{|c|}{ Level Kriteria } & \multirow{2}{*}{ Warna } & \multirow{2}{*}{ Risk Level } \\
\cline { 3 - 5 } & & $(\mathrm{L})$ & $(\mathrm{C})$ & $(\mathrm{L})$.(C) & & \\
\hline 1 & Sikap pekerja & 5 & 4 & 20 & & Ekstrim \\
\hline 2 & Kondisi lantai & 3 & 2 & 6 & & Risiko Sedang \\
\hline 3 & Pengelasan & 5 & 2 & 10 & & Risiko Tinggi \\
\hline 4 & Brander oxi acetylene & 5 & 2 & 10 & & Risiko Tinggi \\
\hline 5 & Mesin Bubut & 2 & 2 & 4 & & Risiko Sedang \\
\hline 6 & Gerinda (hand grinding) & 4 & 2 & 8 & & Risiko Tinggi \\
\hline 7 & Mesin gerinda & 4 & 2 & 8 & & Risiko Tinggi \\
\hline 8 & Shear & 2 & 3 & 6 & & Risiko Sedang \\
\hline 9 & Hoistcrane & 3 & 2 & 6 & & Risiko Sedang \\
\hline 10 & Bor & 2 & 2 & 4 & & Risiko Sedang \\
\hline 11 & Panel & 2 & 2 & 4 & & Risiko Sedang \\
\hline 12 & Mesin Roll & 3 & 4 & 12 & & Ekstrim \\
\hline 13 & Handling Bed & 4 & 4 & 16 & & Ekstrim \\
\hline 14 & Coolling Bed & 4 & 3 & 12 & & Risiko Tinggi \\
\hline 15 & Conveyor & 4 & 3 & 12 & & Risiko Tinggi \\
\hline 16 & Stapel & 4 & 3 & 12 & & Risiko Tinggi \\
\hline
\end{tabular}

Dari tabel 4 dapat diketahui terdapat 3 sumber bahaya yang memiliki nilai "Ekstrim", 7 sumber bahaya yang memiliki nilai "Risiko Tinggi", 6 sumber bahaya yang memiliki nilai "Risiko Sedang" dan sumber bahaya yang memiliki nilai "Risiko Rendah" sebanyak 3 temuan. Menurut UNSW Health and Safety (2008), sumber bahaya yang memiliki nilai "Ekstrim" yaitu pada sikap pekerja, Mesin roll, dan Handling Bed harus diprioritaskan untuk mendapat rekomendasi atau usulan perbaikan terlebih dahulu.

\section{Rekomendasi Perbaikan}

Berdasarkanhasil perangkingan risiko, terdapat 3 sumber bahaya yang harus segera diperbaiki, yaitu: Sikap Pekerja, Mesin Roll dan Handling Bed. Oleh karena itu, pada bagian ini akan menjelaskan beberapa rekomendasi perbaikan yang telah didiskusikan (FGD) penulis dengan tim Healt Safety and Environment (HSE) untuk sumber bahaya yang memiliki nilai risiko "Ekstrim" tersebut.

\section{Rekomendasi Perbaikan "Sikap Pekerja"}

Rekomendasi yang diusulkan penulis untuk menanggulangi potensi bahaya yang disebabkan oleh sumber hazard "Sikap Pekerja" yang tidak memenuhi persyaratan standart dalam keselamatan kerja dan prosedur bekerja yang baik, yaitu:

1. Berupa jadwal pelatihan K3 tentang penggunaan APD yang akan diselenggarakan oleh pihak manajemen khusus area Rolling Mill 3. Secara rutin yaitu 3 bulans ekali sehingga hasil dari pelatihan tersebut dapat langsung diaplikasikan oleh pekerja. Bagi para pekerja yang tidak dapat menghadiri pelatihan akan dikenakan sanksi. Bentuk dari sanksi yang akan diberikan pada pekerja yag tidak mengahdiri pelatihan akan dibahas pada Safety Talk

2. Membuat worksheet penggunaan APD di area kerja agar para pekrja dapat membaca apa saja potensi bahaya yang akan mereka alami ketika melakukan suatu pekerjaan dana pa saja APD yang harus dipakai untuk mengurangi risisko terkena akibat dari potensi bahaya yang mungkin akan muncul ketika mereka bekerja

3. Membuat lembar kontrol pelanggaran penggunaan APD di area Rolling Mill 3 sehingga coordinator unit dapat engawasi pekerja agar selalu disiplin menggunakan APD sesuai kegiatan yang dilakukan oleh pekerja di area kerja. Apabila ada pekerja yang melanggar, coordinator unit berhak mencatat pelanggaran tersebut dan menyerahkan hasil lembar kontrol setiap satu minggu sekali ke bagian industrial safety yang kemudian pelanggaran tersebut akan dibahas di kegiatan safety talk

4. Untuk mengontrol berjalannnya program K3 di perusahaan, pihak manajemen perlu mengadakan safety talk setiap satu bulan sekali yang harus dihadiri oleh beberapa petinggi unit kerja dan di dalamnya membahas tentang pelaksanaan K3 di perusahaan, prosedur kerja, kondisi peralatan safety dan reward and punishment bagi pekerja yang mematuhi atau melanggar peraturan. Kegiatan safety talk dipimpin oleh pihak manajemen dan pesertanya hanya terdiri dari perwakilan petinggi dari masing-masing unit yang ada di Rolling Mill 3.

\section{Rekomendasi Perbaikan "Mesin Roll”}

Rekomendasi yang diusulkan dan telah didiskusikan penulis dengan tim Health Safety and EnvironmentI (HSE) untuk menaggulangi potensi bahaya yang disebabkan oleh sumber hazard pada "Mesin Roll" adalah: 
1. Membuat worksheet penggunaan APD di area kerja Mesin Roll agar para pekerja dapat membaca apa saja potensi bahaya yang akan mereka alami ketik melakukan pekerjaan tersebut.

2. Melarang pekerja selain area Mesin Rolli atau bukan ahlinya mendekati/ melintas area tersebut

3. Memberi speaker pada area Mesin Roll yang berguna untuk memperjelas komunikasi antara pulpit dengan ooperator Mesin Roll pada saat proses produksi

\section{Rekomendasi Perbaikan "Handling Bed"}

Untuk menanggulangi potensi bahaya yang disebabkan oleh sumber hazard pada area "Handling Bed", maka rekomendasi yang diusulkan adalah:

1. Melakukan pemeriksaan APD sebelum bekerja

2. Saling mengingatkan para pekerja untuk selalu memakai APD

3. Tidak melakukan aktifitas pekerjaan ketika tubuh sedang sakit

4. Melakukan perbaikan terhadap mesin-mesin yang sudah rusak atau abnormal

5. Menggunakan alat pengikat besi beton (gancu) yang sesuai dengan ukuran tubuh masingmasing pekerja

6. Memakai APD yangs esuai dengan standart prosedur

\section{PENUTUP}

Kesimpulan yang dapat diambil dari penelitian ini adalah sebagai berikut :

1. Setelah melakukan analisis menggunakan metode HAZOP maka terdapat 42 temuan potensi bahaya dai area rolling mill yang kemudian digolongkan menjadi 16 sumber bahaya (Hazard) yang meliputi : Sikap pekerja, Kondisi lantai, Pengelasan, Brander Oxi Acetyline, Mesin bubut, Mesin gerinda tangan (Hand Grinding), Mesin gerinda, Shear,Hoistcrane, Bor, Panel listrik, Mesin roll, Handling Bed, Colling Bed, Conveyor, dan Stapel. Kemudian dari 16 sumber Hazard tersebut, risiko yang tergolong "Ekstrim" berdasarkan Likelihood dan Consequences adalah sebanyak 3 sumber bahaya yaitu :Sikap pekerja, Mesin roll, Handling Bed.
2. Untuk mengurangi jumlah kecelakaan kerja karyawan maka sumber Hazard yang memiliki nilai "Ekstrim" harus diprioritaskan untuk mendapatkan rekomendasi atau usulan perbaikan terlebih dahulu diantaranya : memeperbarui Standart Operating Prosedure (SOP), membuat Worksheet penggunaan APD di area kerja dan membuat lembar kontrol karyawan.

\section{DAFTAR PUSTAKA}

Prakoso, A. B. (2016). Hazard And Operability Study (HAZOP) Dan Safety Integrity Level (SIL) Dengan Metode Fault Tree Analysis (FTA) Pada Fuel Gas Superheat Burner Unit Ammonia PT. Petrokimia Gresik. Institut Teknologi Sepuluh Nopember.

Wartono, T., Pamungkas, I. B., Lestari, T., Trisyulianti, E., Suryaratri, D. R., Heny, K., ... Nawawinetu, E. D. (2017). Pengaruh Keselamatan Dan Kesehatan Kerja (K3) Terhadap Kinerja Karyawan Pt. Haleyora Powerindo Pekanbaru. Jom Fisip, 3(2), 399404.https://doi.org/10.1016/j.msea.2012.08. 091

UNSW Health and Safety (2008). Risk Management Program. Canberra: University of New South Wales.

http://www.ohs.unsw.edu.au/ohsriskmanag ement/index.html .Diakses pada 24 juli 2020

Wartono, T., Pamungkas, I.B., Lestari., Trisyulianti, E., Suryarantri, D. R., Heny, K., Nawawinetu, E. D. 2017. Pengaruh keselamatan dan kesehatan kerja (K3) Terhadap Kinerja Karyawan Pt. Haleyora Powerindo. Pekanbaru 


\section{Lampiran 1}

Tabel 5. Hazop Analysis Mesin Roll

\begin{tabular}{|c|c|c|c|c|c|c|c|c|c|c|c|}
\hline Item & Function & Parameter & Guide Word & Deviation & Causes & Consequence & Safeguards & $\mathrm{C}$ & $\mathrm{L}$ & RR & Recommendation \\
\hline roll guide & \begin{tabular}{|l} 
sebagai \\
pengatur \\
arah billet
\end{tabular} & flow & no & no flow & $\begin{array}{l}\text { roller tidak } \\
\text { berputar }\end{array}$ & $\begin{array}{l}\text { jalur billet tidak } \\
\text { sesuai/menabrak } \\
\text { mesin roll berikutnya } \\
\text { (terjadi missroll) }\end{array}$ & $\begin{array}{l}\text { alarm, gunting } \\
\text { otomatis }\end{array}$ & 4 & 3 & 12 & $\begin{array}{l}\text { cek dan penjadwalan } \\
\text { maintenance rutin }\end{array}$ \\
\hline twist roll & $\begin{array}{l}\text { sebagai } \\
\text { exit billet }\end{array}$ & flow & no & no flow & $\begin{array}{l}\text { salah satu } \\
\text { atau semua } \\
\text { part } \\
\text { berhenti }\end{array}$ & \begin{tabular}{|l|} 
jalur keluar billet tidak \\
sesuai/menabrak \\
mesin roll berikutnya \\
(terjadi missroll)
\end{tabular} & $\begin{array}{l}\text { alarm,gunting } \\
\text { otomatis }\end{array}$ & 4 & 3 & 12 & $\begin{array}{l}\text { cek dan penjadwalan } \\
\text { maintenance rutin }\end{array}$ \\
\hline boma & \begin{tabular}{|l|} 
sebagai \\
pengantar \\
awal billet \\
masuk roll
\end{tabular} & komponen & part of & part off & $\begin{array}{l}\text { salah satu } \\
\text { atau semua } \\
\text { part } \\
\text { sesak/aus }\end{array}$ & $\begin{array}{l}\text { arah jalur masuk billet } \\
\text { tidak sesuai (terjadi } \\
\text { missroll) }\end{array}$ & $\begin{array}{l}\text { pengawasan } \\
\text { manual oleh } \\
\text { operator }\end{array}$ & 3 & 3 & 9 & $\begin{array}{l}\text { cek sebelum } \\
\text { digunakan dan } \\
\text { melakukan } \\
\text { pergantian rutin }\end{array}$ \\
\hline \multirow[t]{2}{*}{ cooller } & \multirow[t]{2}{*}{$\begin{array}{l}\text { pendingin } \\
\text { mesin roll }\end{array}$} & \multirow[t]{2}{*}{ pressure } & more & $\begin{array}{c}\text { more } \\
\text { pressure }\end{array}$ & $\begin{array}{l}\text { temperatur } \\
\text { billet rendah }\end{array}$ & $\begin{array}{l}\text { roll putus, bearing roll } \\
\text { rusak (terjadi missroll) }\end{array}$ & \begin{tabular}{|l|} 
water pressure \\
gauge,valve \\
control
\end{tabular} & 3 & 3 & 9 & $\begin{array}{l}\text { cek pipa air } \\
\text { pendingin, valve } \\
\text { control }\end{array}$ \\
\hline & & & less & $\begin{array}{c}\text { less } \\
\text { pressure }\end{array}$ & $\begin{array}{l}\text { mesin } \\
\text { terlalu panas }\end{array}$ & $\begin{array}{l}\text { mesin panas, grease } \\
\text { kering (terjadi } \\
\text { missroll) }\end{array}$ & \begin{tabular}{|l|} 
water pressure \\
gauge,valve \\
control
\end{tabular} & 3 & 3 & 9 & $\begin{array}{l}\text { cek pipa air } \\
\text { pendingin, valve } \\
\text { control }\end{array}$ \\
\hline risbar & $\begin{array}{l}\text { tempat roll } \\
\text { guide }\end{array}$ & level & no & no level & $\begin{array}{l}\text { risbar } \\
\text { berkarat, } \\
\text { putus, dan } \\
\text { aus }\end{array}$ & $\begin{array}{l}\text { arah jalur masuk billet } \\
\text { tidak sesuai (terjadi } \\
\text { missroll) }\end{array}$ & $\begin{array}{l}\text { pengawasan } \\
\text { manual oleh } \\
\text { operator }\end{array}$ & 4 & 3 & 12 & $\begin{array}{l}\text { cek dan penjadwalan } \\
\text { repair rutin }\end{array}$ \\
\hline top chuck & $\begin{array}{l}\text { chuck roll } \\
\text { atas }\end{array}$ & level & no & no level & roll putus & $\begin{array}{l}\text { arah jalur masuk billet } \\
\text { tidak sesuai (terjadi } \\
\text { missroll) }\end{array}$ & setting filler & 4 & 3 & 12 & $\begin{array}{l}\text { cek dan penjadwalan } \\
\text { repair rutin }\end{array}$ \\
\hline $\begin{array}{l}\text { bottom } \\
\text { chuck }\end{array}$ & $\begin{array}{l}\text { chuck roll } \\
\text { bawah }\end{array}$ & level & no & no level & roll putus & $\begin{array}{l}\text { arah jalur masuk billet } \\
\text { tidak sesuai (terjadi } \\
\text { missroll) }\end{array}$ & setting filler & 4 & 3 & 12 & $\begin{array}{l}\text { cek dan penjadwalan } \\
\text { repair rutin }\end{array}$ \\
\hline $\begin{array}{l}\text { top block } \\
\text { bearing }\end{array}$ & $\begin{array}{l}\text { rumah } \\
\text { bearing } \\
\text { roll atas }\end{array}$ & komponen & part of & part off & $\begin{array}{l}\text { bearing } \\
\text { pecah }\end{array}$ & $\begin{array}{l}\text { roll tidak berputar } \\
\text { (terjadi misroll) }\end{array}$ & greasing & 3 & 3 & 9 & $\begin{array}{l}\text { cek dan greasing } \\
\text { secara rutin }\end{array}$ \\
\hline $\begin{array}{l}\text { bottom } \\
\text { block } \\
\text { bearing }\end{array}$ & $\begin{array}{l}\text { rumah } \\
\text { bearing } \\
\text { roll bawah }\end{array}$ & komponen & part of & part off & $\begin{array}{l}\text { bearing } \\
\text { pecah }\end{array}$ & $\begin{array}{l}\text { roll tidak berputar } \\
\text { (terjadi misroll) }\end{array}$ & greasing & 3 & 3 & 9 & $\begin{array}{l}\text { cek dan greasing } \\
\text { secara rutin }\end{array}$ \\
\hline $\begin{array}{l}\text { bearing } \\
\text { seal }\end{array}$ & $\begin{array}{l}\text { bearing } \\
\text { seal }\end{array}$ & komponen & part of & part off & $\begin{array}{l}\text { bearing } \\
\text { pecah }\end{array}$ & $\begin{array}{l}\text { bearing kemasukan air, } \\
\text { roll tidak berputar } \\
\text { (terjadi missroll) }\end{array}$ & $\begin{array}{l}\text { memberi talang } \\
\text { air }\end{array}$ & 3 & 3 & 9 & $\begin{array}{l}\text { pembuatan talang } \\
\text { permanen }\end{array}$ \\
\hline
\end{tabular}

Tabel 6. Hazop Analysis Handling Bed

\begin{tabular}{|c|c|c|c|c|c|c|c|c|c|c|c|}
\hline Item & Function & Parameter & uide Word & Deviation & Causes & Consequence & Safeguards & $\mathrm{C}$ & $\mathrm{L}$ & $\mathrm{RR}$ & Recommendation \\
\hline rollgang & $\begin{array}{l}\text { mobilitas } \\
\text { besi beton }\end{array}$ & komponen & part of & part off & $\begin{array}{l}\text { kondisi roll } \\
\text { berlubang/ } \\
\text { aus }\end{array}$ & lajur besi beton mac & noun & 2 & 1 & 2 & $\begin{array}{l}\text { pergantian rutin } \\
\text { atau restorasi } \\
\text { sementara } \\
\text { (welding) } \\
\end{array}$ \\
\hline chain & $\begin{array}{l}\text { penyambu } \\
\text { ng/trans } \\
\text { misi antar } \\
\text { rollgang }\end{array}$ & komponen & part of & part off & putus & lajur besi beton mac & noun & 2 & 1 & 2 & $\begin{array}{l}\text { cek dan } \\
\text { penjadwalan } \\
\text { maintenance } \\
\text { rutin } \\
\end{array}$ \\
\hline sprocket & $\begin{array}{l}\text { transmisi } \\
\text { rollgang }\end{array}$ & komponen & part of & part off & spy rusak & lajur besi beton mac & noun & 2 & 2 & 4 & $\begin{array}{l}\text { cek dan } \\
\text { penjadwalan } \\
\text { maintenance } \\
\text { rutin } \\
\end{array}$ \\
\hline ucp & $\begin{array}{l}\text { bantalan } \\
\text { rollgang }\end{array}$ & komponen & part of & part off & grease kering & $\begin{array}{l}\text { bearing tidak } \\
\text { berfungsi }\end{array}$ & greasing awal & 2 & 1 & 2 & $\begin{array}{l}\text { cek dan } \\
\text { penjadwalan } \\
\text { maintenance } \\
\text { rutin }\end{array}$ \\
\hline ucp bolt & pengunci & komponen & part of & part off & nut kendor & lajur besi beton mac & welding & 2 & 1 & 2 & cek dan welding \\
\hline $\begin{array}{l}\text { chain } \\
\text { conveyor }\end{array}$ & $\begin{array}{l}\text { mobilitas } \\
\text { besi beton }\end{array}$ & komponen & part of & part off & putus & $\begin{array}{l}\text { terjadi tumpukan } \\
\text { besi beton }\end{array}$ & noun & 3 & 2 & 6 & $\begin{array}{l}\text { cek dan } \\
\text { penjadwalan } \\
\text { maintenance } \\
\text { rutin }\end{array}$ \\
\hline
\end{tabular}




\section{lampiran 2}
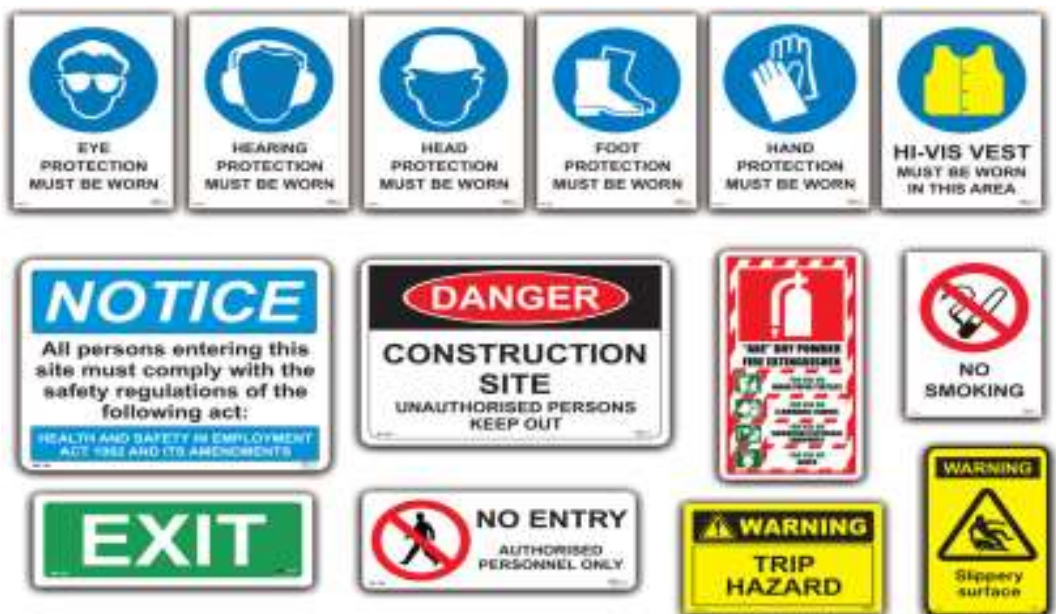

Gambar 3. Penggunaan Worksheet APD

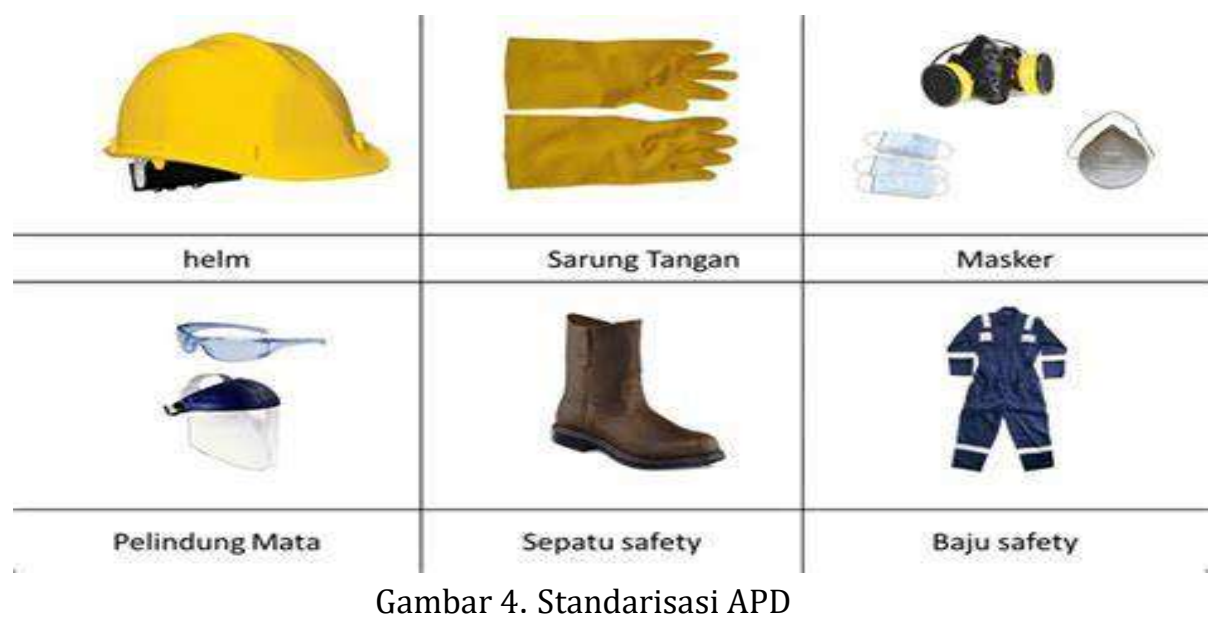

